\title{
Comparison of different electrocardiographic criteria for the detection of previous myocardial infarction in relation to infarct characteristics as assessed with cardiovascular magnetic resonance imaging
}

\author{
Caroline Jaarsma ${ }^{1,2^{*}}$, Sebastiaan C Bekkers ${ }^{1,3}$, Zaki Haidari ${ }^{1,3}$, Martijn W Smulders ${ }^{1,3}$, Patricia J Nelemans ${ }^{3,4}$, \\ Anton Gorgels ${ }^{1,3}$, Harry J Crijns ${ }^{1,3}$, Joachim E Wildberger ${ }^{2,3}$, Simon Schalla $a^{1,3}$ \\ From 16th Annual SCMR Scientific Sessions \\ San Francisco, CA, USA. 31 January - 3 February 2013
}

\section{Background}

The electrocardiogram (ECG) is often used as initial test to detect or rule out previous myocardial infarction (MI). Although different ECG-criteria with considerable heterogeneity are used for this purpose, their accuracy is not well described. We aimed to determine the diagnostic accuracy of four commonly used ECG-criteria for detecting previous MI: 1) the universal definition of previous MI, 2) the Minnesota ECG-code (MC), 3) the Selvester QRS-score, and 4) assessment by cardiologists, using delayed-enhancement cardiovascular magnetic resonance imaging (DE-CMR) as reference standard. Also the effect of different ECG and infarct characteristics on detecting previous MI were evaluated.

\section{Methods}

The 3-month follow-up ECGs of 78 first, reperfused STelevation MI (STEMI) patients were pooled with ECGs of 36 healthy controls. All 114 ECGs were randomly analyzed, blinded to clinical and DE-CMR data. Sensitivity, specificity, and diagnostic accuracy were determined for the universal definition, MC, Selvester QRS-score, and visual assessment by two cardiologist with $>10$ years of clinical experience. DE-CMR (104 \pm 11 days post MI) showed hyperenhancement matching the infarct-related artery (IRA) territory in all patients. The effect of ECG patterns and infarct characteristics on probability of MI

${ }^{1}$ Cardiology, Maastricht University Medical Center, Maastricht, Netherlands Full list of author information is available at the end of the article detection was evaluated using logistic regression analysis. For anterior MI (LAD 31\%), leads I, aVL, V1-V6 and for non-anterior MI (LCx 14\%, RCA 55\%) leads II, III, aVF, V1-V2 were evaluated.

\section{Results}

The sensitivity of the universal definition, MC, Selvester QRS-score, and cardiologists was 33\%, 79\%, 88\%, and $67 \%$, specificity was $97 \%, 72 \%, 31 \%$, and $89 \%$, diagnostic accuracy was $54 \%, 77 \%, 70 \%$, and $74 \%$, respectively (Figure 1). Probability of detection of MI by cardiologists increased with an increasing number (odds ratio [OR] 2.00 (95\% confidence interval [CI] 1.30-3.09)), width (OR 1.02 (95\%CI 1.01-1.03)), and depth (OR 1,16 (95\%CI 1.07-1.27)) of Q-waves in anterior MI and Q- or R-waves in non-anterior MI $(\mathrm{p}<0.01$ for all). Increasing infarct size and transmurality also increased the likelihood of detecting previous MI (OR 1.15 (95\%CI 1.06-1.25), $\mathrm{p}<0.01$, and OR 1,05 (95\%CI 1.01-1.08), $\mathrm{p}=0.01$ ). Five infarctions $(6 \%)$ were not detected by any of the ECGcriteria (infarct size and transmurality ranging from $1.5-8.5 \%$ and $32-86 \%$, respectively).

\section{Conclusions}

For detecting previous MI, the time-consuming $\mathrm{MC}$ and visual assessment by cardiologists achieved the best and similar diagnostic accuracies. The likelihood of detecting previous MI increased with an increasing number, depth, and width of Q-waves in anterior MI and Q- or 

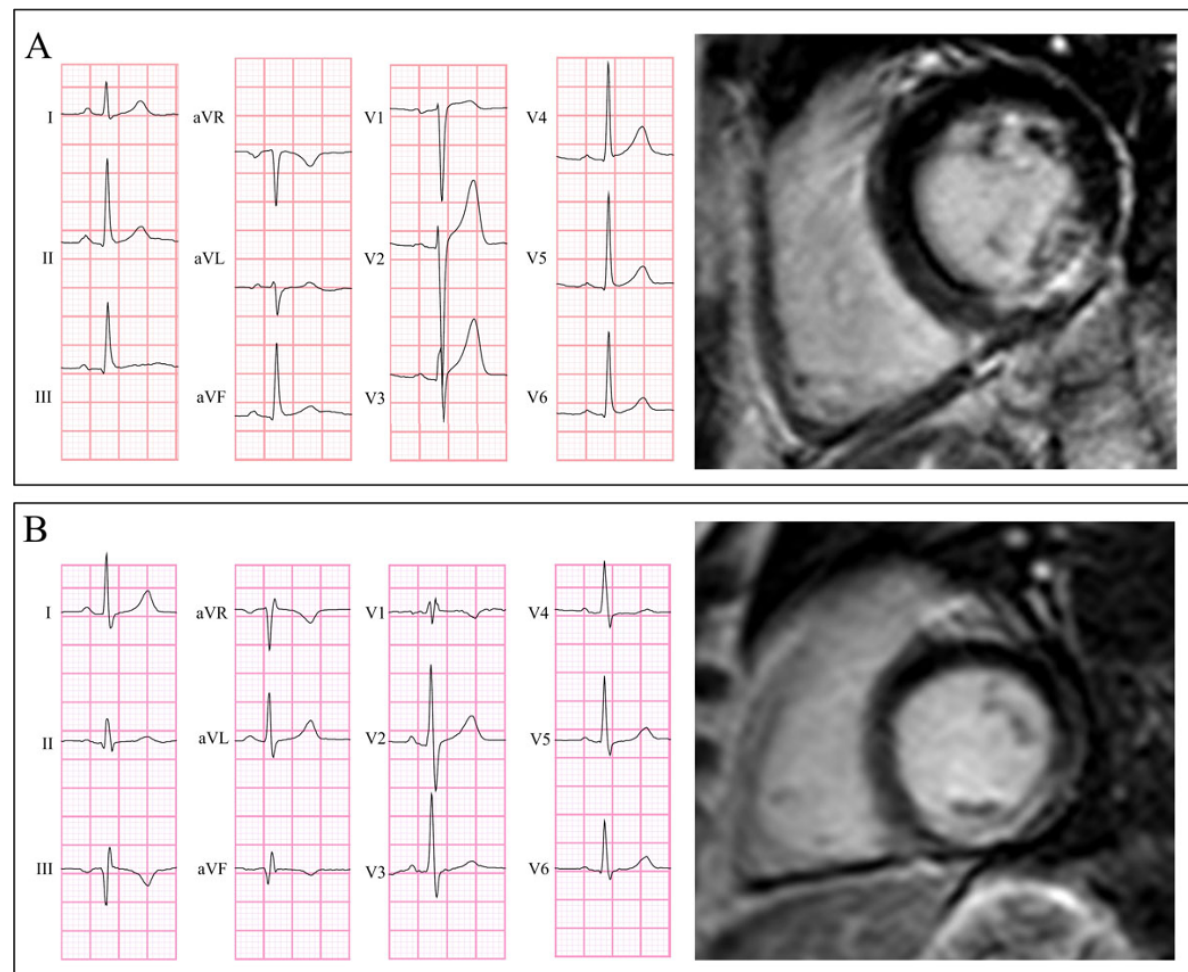

Figure 1 Electrocardiogram and corresponding delayed-enhancement cardiovascular magnetic resonance short axis view of an undetected (A) and a detected (B) myocardial infarction. Electrocardiogram (ECG) and corresponding cardiovascular magnetic resonance delayed-enhancement short axis view of a 58-year-old man with an LCX-related myocardial infarction (infarct size $8.5 \%$ of the left ventricle and $65 \%$ transmural) that was not detected by any of the ECG-criteria (A) and a 55 year-old man with an LCx-related myocardial infarction (infarct size $7.5 \%$ of the left ventricle and $51 \%$ transmural) that was detected by all four ECG-criteria (B).

R-waves in non-anterior MI, as well as increasing infarct size and transmurality. However, a considerable number of infarctions remain undetected by all ECG-criteria.

\section{Funding}

None.

\section{Author details \\ ${ }^{1}$ Cardiology, Maastricht University Medical Center, Maastricht, Netherlands. ${ }^{2}$ Radiology, Maastricht University Medical Center, Maastricht, Netherlands. ${ }^{3}$ Cardiovascular Research Institute Maastricht (CARIM), Maastricht University, Maastricht, Netherlands. ${ }^{4}$ Epidemiology, Maastricht University, Maastricht, Netherlands.}

Published: 30 January 2013

doi:10.1186/1532-429X-15-S1-E70

Cite this article as: Jaarsma et al:: Comparison of different electrocardiographic criteria for the detection of previous myocardial infarction in relation to infarct characteristics as assessed with cardiovascular magnetic resonance imaging. Journal of Cardiovascular Magnetic Resonance 2013 15(Suppl 1):E70.

\section{Submit your next manuscript to BioMed Central and take full advantage of:}

- Convenient online submission

- Thorough peer review

- No space constraints or color figure charges

- Immediate publication on acceptance

- Inclusion in PubMed, CAS, Scopus and Google Scholar

- Research which is freely available for redistribution 